\title{
The Student-Self Oriented Learning Model as an Effective Paradigm for Education in Knowledge Society
}

\author{
Vladimir A. Fomichov \\ Department of Intelligent Monitoring Systems, Institute No. 3 Control Systems \\ Informatics and Electric Power Industry, Moscow Aviation Institute (National Research University) \\ Orshanskaya street 3, 121552 Moscow, Russia \\ E-mail: vfomichov@gmail.com, https://www.researchgate.net/profile/Vladimir_Fomichov \\ Olga S. Fomichova \\ Division "Dialogue of Sciences", State Budget Professional Educational Institution "Sparrow Hills" \\ Universitetsky prospect 5, 119296 Moscow, Russia
}

Keywords: emotional intelligence, STEM education, STEAM education, creativity development, development of figurative reasoning, art cognitonics, thought producing self, early socialization of children, theory of dynamic conceptual mappings, system of emotional-imaginative teaching, cognitive engagement, serendipity, anthropocentric approach to education

Received: June 21, 2018

\begin{abstract}
Proceeding from broadly accepted role of emotional intelligence (EI) in professional and personal life, the paper suggests a new learning model (LM) called Student-Self Oriented LM (SSOL-model). It is defined as the model being beneficial for self-cognition and self-construction through the prism of the acquired knowledge and life experience. Two successful implementations of the SSOL-model are shortly described: the system of emotional-imaginative teaching (the EIT-system) developed by the authors in the 1990s and expanded in the 2000s and art cognitonics. The EIT-system is underpinned by the authors' Theory of Dynamic Conceptual Mappings (the DCM-theory). The EIT-system includes an original method of developing figurative thinking and creativity at the lessons of second language (English for Russian children), literature and poetry in English and Russian, symbolic language of painting, and communication culture. It is stated that this method may be used as an effective starting framework of STEAM education. It is mentioned that the DCM-theory and the EIT-system became the starting point for developing the foundations of a new scientific discipline called cognitonics. The basic principles of art cognitonics - a well developed branch of cognitonics and the concept of cognitive engagement are described. The significance of art cognitonics for helping the learners to answer the encountered moral questions is explained. The broad possibilities of designing intelligent tutoring systems (ITSs) of new generation are indicated. These are culture and moral experience oriented systems aimed at developing figurative thinking, creativity, early socialization and helping the students to find in the outstanding art works the answers to emerging moral questions. An original, detailed script of an ITS contributing to early socialization of the learners is described, its literary source is the fairy-tale "Sleeping Beauty". Since the sphere of using the SSOL-model is not restricted, it is suggested to interpret this model as an effective paradigm for education in knowledge society and a strong support to anthropocentric approach to education in the digital age.
\end{abstract}

Povzetek: Predstavljeno je samo-modeliranje študentov kot metoda učenja v družbi znanja.

\section{Introduction}

The progress of science and technology in the end of the $20^{\text {th }}$ - the beginning of the $21^{\text {st }}$ century has posed new demands to education. Likely, the most significant demand is the formation of the preconditions of mastering several professions during the life: for the most part of people, it is impossible in knowledge society (or smart society) to have only one profession during the life. The second most significant demand seems to be the ability to quickly generate new knowledge, the skill of integrating knowledge pieces obtained from numerous dispersed information sources, the ability of creative thinking while processing new knowledge and its connections with available knowledge. A popular answer to the challenge of time in the sphere of education is smart learning. Many scholars interpret smart learning as learning with broad use of mobile devices: tablet computers, androids, etc. This definition reflects the focus on technical means of learning. It explicates the essence of technological approach to education in the digital age.

We believe that the following metaphor shows the roots of this approach: it is a consequence of the admiration experienced by the six-year old child just discovered astonishing possibilities of computer. 
There are reasons to believe that the dominant part of the scholars don't notice the fundamental problem of (a) perfecting, improving the principles and methods of teaching and learning, (b) combining these principles and methods with the principles and methods of developing personality of the learners, their system of values. The analysis of scientific literature shows that a high proportion of elementary, middle, and high school students encounter considerable difficulties as concerns grasping the main ideas of the pieces of theory to be studied (see Section 2).

Parallelly with the term "smart learning", the notion "emotional intelligence" (EI) belongs to the set of concepts most often used in scientific publications in the field of education. According to [1], EI is the other kind of smart. The studies carried out during two decades after the birth of this notion in 1995 [25] have shown that EI is the crucial factor distinguishing star performers of various professional roles among all performers.

EI determines the manner of a person to manage behavior, deal with social complexities, and make decisions leading to positive results. EI is the unity of four core skills forming two primary competences: personal competence $(P C)$ and social competence $(S C)$. According to [1], PC is composed by two skills: self-awareness and self-management. The first skill is the ability of a person to accurately perceive his/her emotions and stay away of them as they happen. self-management is the ability of a person to use awareness of his/her emotions for staying flexible and for positively directing his/her behaviour. SC is defined in [1] as the ability of a person to understand other people's moods, behaviour, and motives for improving the quality of his /her relationships. SC is composed by social awareness and relationship management.

During last two decades, the psychologists have discovered a huge role of well-developed EI in taking successful business decisions. That is why now the companies throughout the world pay a very high attention to the state of EI while hiring, promoting, and increasing qualification of their employees [26].

The next term of high significance for education is creativity. The analysis of the literature shows that the scholars from many countries consider the problem of supporting and developing creativity of the learners as a highly acute problem. Until the 2000s, the majority of publications on creativity studied the peculiarities of intelligent activity of outstanding scientists, painters, writers, poets, etc. (see., e.g., [24]). This kind of creativity is often called in modern literature "big C creativity" (BCC), this term was introduced in [34].

However, the realities of information society transforming in many countries into knowledge society (KS) caused the emergence of the term "little C creativity" (LCC). The birth of this term reflects the demand of everyday creative thinking [2]. The two criteria of BCC are the originality and high significance for big groups of people. Creativity demonstrated by children usually is subjective, it is determined by their prior knowledge. An important characteristic of children's creativity is imagination [3].
The realities of KS demand to support and develop LCC in order to increase the proportion of the specialists possessing BCC. But it is not obvious how to achieve this global goal. The paper [33] describes the results of a large scale study carried out in USA and focused on the evolution of average level of intelligence and creativity during two decades, since the early 1990s. This study showed a considerable increase of average intelligence level during two decades. To the contrary, according to this study, the level of creative thinking considerably decreased. The study showed the increase of children's ability to produce ideas and the openness to new ideas until the age of nine. After this moment, these characteristics remain rather stable during approximately one year, and then they steadily decline. Children's curiosity follows the same dynamics.

A considerable diminishment of creativity level discovered in USA [33] became a significant standpoint for the development of an education brand called STEAM education (STEAMed). Here STEAM is an abbreviation for Science, Technology, Engineering, Art, Mathematics. During this decade, the ideas of STEAMed have become rather popular in the USA and South Korea.

During over two decades, we have been looking for more effective principles of teaching and learning in comparison with the broadly used ones. The accumulated theoretical and practical experience shows that modern education as a whole underestimates the significance of basing on EI for making easier for the students grasping central ideas of theoretical materials to be learned and for developing creativity.

The principal aim of this paper is to suggest a new paradigm for education in $\mathrm{KS}$, in particular, for STEAMed. It is the Student-Self Oriented Learning Model (SSOL-model). Our model is called Student-Self oriented, because Self is always emotionally coloured. If we take something close to our heart or understand that it is not our cup of tea, we always experience emotions. Strong emotions leave a semantic trace in our inner world's picture [39].

The proposed SSOL-model has at least two successful implementations. The first one is the System of Emotional-Imaginative Teaching (the EIT-system) underpinned by our Theory of Dynamic Conceptual Mappings. The system is composed by (a) several complex methods combing teaching/learning with the development of the student's personality, (b) an original program of extra-scholastic humanitarian education covering 9 years of continuous studies, where the starting age is five - seven years [6-12, 14-22]. Our new theory and the system of methods became the starting point for developing the foundations of a new scientific discipline called cognitonics [13-18, 22]. The second implementation of the SSOL-model is art cognitonics [16 - 18].

The structure of this article is as follows. Next section describes the related approaches. The principal attention is given to (a) the difficulties encountered by the students trying to grasp the pieces of materials to be learned; (b) the approaches to STEAM education. Section 3 introduces the SSOL-model. Section 4 illustrates one of its components: a conceptual learning environment. Section 
5 interprets the EIT-system as a successful implementation of the SSOL-model. Section 6 outlines a balanced approach to starting and continuing STEAM education, it develops EI, reasoning skills, and creativity. Section 7 interprets art cognitonics as the second successful implementation of the SSOL-model and explains the concept of cognitive engagement. Finally, the prospects of using the EIT-system for designing intelligent tutoring systems developing EI of the learners are discussed. A big part of this article is based on our papers $[17,23]$.

\section{Related approaches}

\subsection{The problem of grasping the materials to be learned}

The analysis of scientific literature shows that a high proportion of elementary, middle, and high school students encounter considerable difficulties as concerns grasping the main ideas of the pieces of theory to be studied, Let's consider the main social consequences of this situation.

1. The US Public Health Service prepared in the year 2000 a report on children's mental health [46]. According to this report, approximately one fifth of children and adolescents experienced problems showing their need for mental health services. One of the main reasons for this need is the intellectual and emotional obstacles on the way of successful learning faced by the school students in conditions of too short time for relaxation and refreshing the brain as a consequence of many-hour interaction with the Internet, in particular, with computer games.

2. Rather often, the breaks of discipline at lessons encountered by the students in the process of grasping the materials to be learned cause the growth of aggressiveness towards the teachers and the classmates with higher grades. The breaks of discipline negatively influence the total learning result of the class. Besides, these breaks and the aggressiveness of some students towards the teacher prevent a considerable part of gifted persons with the abilities of good educator from choosing the profession of teacher for himself/herself.

3. The negative consequences of students' aggressive attitude towards their classmates may be very severe (posting in social networks false information about a classmate, false erotic pictures, etc.) and even tragic in cases of cyber bullying.

4. In many cases, the attacks of young hackers against socially important technical systems may be explained as a result of expressing the aggressiveness. The intelligent power of applied computer systems is being permanently increased. That is why the negative consequences of the hackers' attacks promise to be increasing too. Taking this dangerous tendency into account, and, besides, the aggressiveness of some students towards their classmates and the teachers, a socially very significant task is to find the ways of making easier for the students the grasping of the pieces of theory to be learned (there are reasons to believe that, very often, the experience of success in the process of learning eliminates the student's aggressiveness).

5. In KS, many countries encounter the problem of insufficiently developed social lifts. The following scientific fact says about the high significance of solving this problem: in different strata of people living in one country, various gifts are distributed approximately in the same way. That is why it would be important to have the situation when the adolescents from different social-economic strata possessing the gifts being crucial for a certain socially significant profession (a medicine, a lawyer, etc.) would enter a university for mastering this profession.

Unfortunately, in many countries the real situation is quite opposite. For instance, it applies to UK. As it is shown in [30], the Organisation for Economic Co-operation and Development (OECD) describes the United Kingdom's troubling social mobility problems [38]: more than 50\% of youngsters will grow up to have the same salary as their father. The Sutton Trust [45] shows that 53\% of the UK's most influential people were independently educated, including $24 \%$ of university vice-chancellors, $32 \%$ of Members of Parliament, $51 \%$ of medical consultants, $54 \%$ of top journalists, $70 \%$ of High Court judges... when only $7 \%$ of the UK population are.

\subsection{From STEM to STEAM education}

The U.S. National Academies of Science, Engineering and Medicine prepared in 2005 a report underlining that for the global leadership of the U.S., their students would be better prepared in STEM disciplines (Science, Technology, Engineering, Mathematics). As a reaction, President Obama announced in 2009 the initiative called "Educate to Innovate". This initiative, first of all, proposed to increase federal investment in STEM education and to prepare 100,000 new STEM teachers by 2021. Regretfully, the U.S. Department of Education stated in the year 2011 that only $16 \%$ of high school students are interested in a STEM profession and had proven a proficiency in mathematics. Besides, $57 \%$ of high school students with initial interest in a STEM-related field lose interest before graduating from high school [28].

A dramatic diminishment of average creativity level discovered in USA [33] demanded a strong compensating response. The idea of response was prompted by the well known fact: the brightest works of art emerged due to the creative acts of consciousness. That is why a way out was seen in including art lessons into STEM curricula. The resolution No. 319 of the U.S. House of Representatives (June 21, 2011) indicated the significance of STEAM education (Science, Technology, Engineering, Art, Mathematics) and asked the Director of NSF to develop a STEM to STEAM committee $[35,41]$. It seems that this resolution is underpinned not only by the ideas to increase the creativity of young generation but also by the idea to make the STEM disciplines more attractive for middle and 
high school students and, as a consequence, to contribute to solving the main task: to increase the effectiveness of STEM education and the proportion of young people choosing a STEM-related profession. During recent years, the ideas of STEAMed have become rather popular in several other countries, first of all, in South Korea[31, 32].

Our analysis of publications on implementations of STEAMed shows the lack of adequate theoretical foundations of creating the effective cognitive preconditions of STEAMed in kindergartens and elementary school. We mean here the ability to perceive beauty in various manifestations (the openness to perceiving beauty) and realization of basic creative mechanisms being equally necessary for future artists, mathematicians, dress designers and airplane designers. The significance of developing creativity in kindergartens and elementary school is underlined in [33].

The scientific literature presents only a rather restricted spectrum of the approaches to developing creativity in pre-school and elementary school. The prevailing approach is the plays of young children with physical objects, including the sorting of objects in accordance with certain properties (colour, size, etc.). During last decades, it has been possible to observe the shift from using for sorting mechanical objects to the usage of plants, sands, and water [27]. However, rather often the parents of young children (in particular, in Singapore) are anxious about the lack of learning outcomes as a result of the lessons when young children just free play [27].

That is why a topical problem is to discover the effective ways of developing the creativity at pre-school and elementary school lessons with considerable learning outcome.

\section{Student-self oriented learning model}

We believe that modern education may find the ways to effectively deal with numerous open problems as a result of accepting a new LM taking into account the significance of EI in professional and personal life.

The broadly accepted student oriented LM determines the activities launched by the goal to discover the world: acquisition of information, information processing, knowledge construction. The resulting activities are constructing a new text and constructing a new sense. Then the achieved cognitive-emotional state is as follows: a student is well-educated but not intellectually and spiritually mature.

Discovering the world is based on a brand-new culture on the basis of digital opportunities and ideology. Its essence is to catch up with new technologies (but not to find one's way and incorporate it into modern reality as a new vision). It is underpinned by the curiosity and strong aspiration to discover the digital world, on the one hand, and by the desire to emulate the grown-ups and become as smart and powerful as the grown-ups or even much smarter and much more powerful.

The concept of Self is based upon our images of ourselves. The Self develops as it interacts with the most important of environmental influences. Through this social interaction the Self defines itself as a social being, which influences and is influenced by others [37].

Student-self oriented learning model (SSOL-model) is defined as the model being beneficial for self-cognition and self-construction through the prism of the acquired knowledge and life experience [17].

Natural language is the tool for constructing social reality [44]. The Self develops through the social interaction and co-creative work, because creative work suggests personal involvement and is underpinned with strong emotions (e.g., inspiration). The process is always emotionally coloured.

Under the framework of standard model, the process of knowledge acquisition often seems to the students to be first rather gloomy (no interest, no personal involvement), then pleasant. In case with the SSOL-model, the process of learning seems to the students to be pleasant and curious from the very beginning. Afterwards it is filled with never ending delight. The new model helps to exclude from the perception of educational process such characteristic as "gloomy". It arises the interaction with the environmental influences and causes cognitive engagement of the students.

This idea is intuitively clear to very many experienced lecturers. EI suggests Self, because Self is always emotionally coloured. One is never tired when the subject of the conversation (or lecture) touches his/her Self in a positive and curious way. You are never tired if we are speaking about you and want to know your life experience, you are in the centre of attention.

Strength of materials (or mechanics of materials) is known as one of most difficult disciplines for the university students - future engineers. However, 62 years ago one scientist found a thrilling way to introduce basic ideas of his discipline. This scientist is Charles Seim, he wrote the article "A Stress Analysis of a Strapless Evening Gown" in the year 1956. This article was published in the book "A Stress Analysis of a Strapless Evening Gown and Other Essays for a Scientific Age" (Robert A. Baker, 1969, 212 pages). The translation of this book under the title "The physicists are joking" became very popular in Russia in the 1970s.

The core of the proposed model consists of selfcognition, self-construction, and self-regulation of selfconscious emotions. Let's explicate these notions. Selfcognition is active transfiguration but not passive reflexion. Self is constructed through the interaction with the world (through the discovery of the world). The particular facets of the personality are improved as a result of new experience and as a result of processing the semantic trace left by a strong emotion caused by that new experience (it is the improvement of emotional experience). Self is always coloured by emotions. That is why this semantic trace deepens the emotional experience and, as a consequence, improves the emotional intelligence of the student $[18,39]$.

Firstly, the realization of this new model leads to Student - Digital World balanced partnership. It means that the spiritual maturity and cultural level of the student become equal to the outstanding breakthrough in digital 
technologies. Secondly, the realization of the new model leads to the improvement of serendipity and turns information into serendipitous information (unexpected but desirable). Serendipity is the ability to make pleasant and unexpected discoveries entirely by chance [29, 43]. It leads to much higher level of socialization and to much higher level of responsibility.

To sum up, the suggested model determines the humanistic filling of education in the digital world. The new model suggests:

a conceptual learning environment instead of a memorization-based one (it means making emotionally coloured the concepts to be learned and, as a consequence, making much easier grasping these concepts);

the methods of achieving cognitive engagement of the students;

- a system of self-oriented questions in the process of knowledge acquisition;

the methods of encouraging the students to discover the world aimed at self-cognition and selfconstruction;

a method of teaching the students how to process serendipitous information.

\section{Examples: a conceptual learning environment for studying second language}

Example 1. The experience shows that it is very difficult for five - six year old Russian students to understand why they should use in simple phrases different words "am", "is", "are" and how one should combine these words with the words "I", "you", "he", "she", "it", "we", "they". Our approach to this problem is as follows. Assume that a teacher knows that her young student Julia has a beautiful dress for theatre, a dress for kindergarten, and a dress for a bathroom. Julia agrees that she never doubts what dress to wear. Then the words "am", "is", "are" may be called the different dresses of the verb "to be" (children at this age have very vivid imagination). Besides, "am" may be called a dress for visiting the house where the word "I' lives, "are" - a dress for visiting the house where the words "you", "we", "they" live, and "is" - a dress for visiting the house where the words "he", "she", "it" live [8].

Example 2. In English grammar we have the Present Continuous Tense. We propose a new approach to explaining this Tense, the motive is that our many year experience has shown that this approach provides the possibility to minimize the number of errors. The peculiarity of this piece of grammar for Russian learners is the lack of similar tense in the grammar of Russian language. This tense is very important tense, because it reveals the emotional state of an interlocutor and emotionally colours the speech. It is possible to call it the Emotional Tense - the tense which reveals our emotions. For example, saying "Look, she is reading", we attract somebody's attention to something or somebody, because we are not indifferent to it. When we are talking and drinking in a cafe, we say: "I am reading an interesting book now", it means that we are carried away by the book (at least we are not indifferent towards it if we mention it while talking and drinking). We use this tense speaking about the weather, about changing situation, irritation ("You are always wearing my slippers"), to express admiration ("What a nice hat you are wearing!"), personal arrangements, etc.

This tense shows emotionally coloured attitude towards something, it doesn't just state the fact, doesn't denote something which is true in general. The personal involvement is high, the state of minute is obvious (when somebody scoops a precious, significant, or just a particular minute out of the river of time). Due to the usage of the proposed approach at lessons of English as a second language (SL), the Russian students begin to employ this tense eagerly while speaking. It makes the lessons of English grammar socially coloured and more interesting for the students. Besides, this method reveals the essence of the English character.

\section{The system of emotional- imaginative teaching as a successful implementation of the SSOL-model}

In early 1990 s we came to the conclusion that educational potential of young learners (5-6-7 years old) is much higher then it was broadly accepted to believe. The key to more effective realization of this potential should be the ways of establishing a correspondence between a piece of material to be studied and a certain bright fragment of the learner's conceptual picture of the world. We called such correspondences dynamic conceptual mappings $[7,8,13]$. That is why we started in early 1990s a study aimed at finding more effective ways of teaching and learning due to systemic basing on young learners' emotional experience accumulated, in particular, during the breakfasts and lunches, the walks in gardens and parks and along a river, while visiting school and theatres, playing various games, sport activities, etc.

Step by step, we obtained several scientific and practical results of high social significance, and these results stood apart from the principal trends in education of the 1990s and early 2000s [15]. It was done due to our original Theory of Dynamic Conceptual Mappings (the DCM-theory) [7-12, 19-21] and our System of EmotionalImaginative Teaching (the EIT-system), based on the DCM-theory. The EIT-system is aimed at systematic development of EI, reasoning skills, sound creativity, language skills, and communication culture at the lessons of language - mother tongue and SL, literature and poetry in two languages (on the example of Russian and English), symbolic languages of painting, sculpture, garden-park art, classic dance. We have accumulated the 28-year-long successful experience of using the EIT-system in extra education in Russia. Many aspects of the EIT-system are described in our papers published in the proceedings of the First - Fifth international conferences on cognitonics (see, in particular, $[16,17,22,23])$, in the papers [6-11, 13-15, 19-21] and in the monograph [18]. 
Let's consider now such aspects of the EIT-system that concern basing on and developing EI and Self of the students. Self is always creative, because it is a personal way of viewing the world, based on the world's conceptual picture of the beholder and his/her estimation of the events.

Example. The famous Russian poet Boris Pasternak gives the picture of the early spring, writing:

- Is it only dirt you notice

- Does the thaw not catch your glance?

We ask the students what makes Pasternak think that the thaw is beautiful. The answers of young students ( 7 years old) are as follows:

- The thaw is like a herd of dapple grey deer basking in the spring sun;

- It is like a surface of the moon dotted with craters;

- A table served for breakfast with blue cups and black ice tea with a piece of Sun.

This approach helps young students to understand and penetrate the very essence of beautiful poetical lines written by the great poet. Besides, it expands their way of viewing the world, makes the surrounding world much more colourful, and their way of viewing it much more creative. This approach helps them also to understand painting (and modern painting, in particular).

An acute educational problem is early socialization of children in KS. Let's illustrate the approach of the EITsystem to solving this problem.

Example. In the fairy-tale "Snow White" the Queen asks: "Looking-glass on the wall who is fairest of us all?". The students are asked whether it is a question in fact or she is sure that she is beautiful. The young students give the following explanations:

- If she wants to know as a researcher, she wouldn't be furious.

- She does it every morning simultaneously with having coffee or brushing her hair. It means that she is sure in the answer.

- She is selfish and she doesn't think about the good for the others, even the King. That is why she can't be beautiful. May be attractive, like Cinderella's sisters, but not beautiful.

- When the hunter promises to take Snow White into the woods, he doesn't promise to kill her. But the Queen is sure that he does. It is a cognitive trap: she doesn't expect anybody to protest, to disagree, to disobey her. It is one more prove that she is selfish and doesn't listen to anyone. It will mislead her.

Our educational results obtained in the 1990s due to the EIT-system were interpreted during last decade as a significant contribution to developmental psychology and to positive movement in psychology $[6,9,10,15,16]$.

\section{A balanced approach to developing emotional intelligence, reasoning skills, and creativity as an effective framework for STEAM education}

Comparing our results with the approaches to initial, start stages of STEAMed described in the papers from North America and Asia, we have come to the conclusion that now STEAMed has no appropriate theory of start mechanism. Showing the diminishment of creativity level in USA during two last decades, Kim [33] indicated the necessity of starting the development of creativity in kindergartens. An important role in achieving this goal is to be played by calm, free, friendly atmosphere at lessons $[33,34]$.

We believe that now, as a whole, cognitive potential of five-seven year olds is underestimated. The analysis shows that the DCM-theory and the EIT-system may be interpreted as an effective theoretical framework for starting STEAMed. Figure 1 shows the system of cognitive transformations corresponding to creating initial cognitive preconditions of effective STEAMed concerning a concrete young learner.

The principal advantages of our approach to creating the preconditions of effectively starting STEAMed are as follows. Young learners (five-seven years old) get accustomed to the beauty expressed in various ways. It is well known that it is highly important not only for the painters, sculptors, poets, dress designers but also for mathematicians, physicists, designers of ships and airplanes to have a well developed feeling of harmony.

A fundamental significance of our approach for STEAM education is determined also by the formulation of the cognitive precondition of the situation when it is possible to start systematic acquaintance of children with the computer. It is the realization of the ThoughtProducing Self of the child [12, 13, 18, 20].

As a consequence of getting a developed figurative reasoning (due to of a kind of intellectual game, intellectual competition), young learners get a developed creativity. Our approach to early creativity development excellently correlates with the opinion of Piaget [40] about the significance of "reflective abstraction'. i.e., about the crucial role of processing and constructing knowledge in the course of mental actions performed on the perceived and imaginary objects and causing generation of new ideas. 


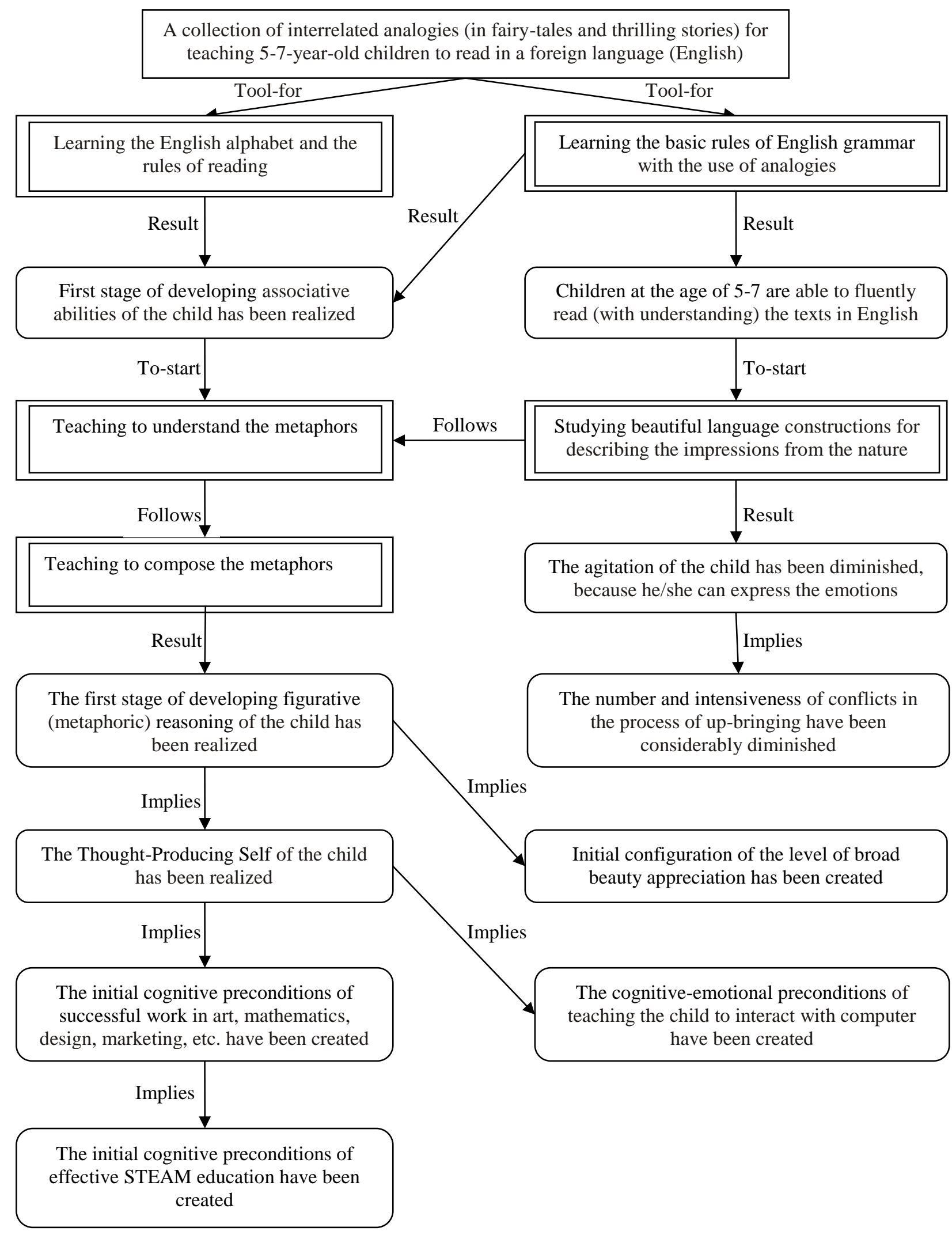

Figure 1: A map of cognitive transformations corresponding to creating initial cognitive preconditions of effective STEAM education. 
As for early socialization, the young students became careful, tactful, thoughtful, they acquire the feeling of empathy and start appreciating the harmony in everything, including human relationships. In this case

\section{Learner's Self}

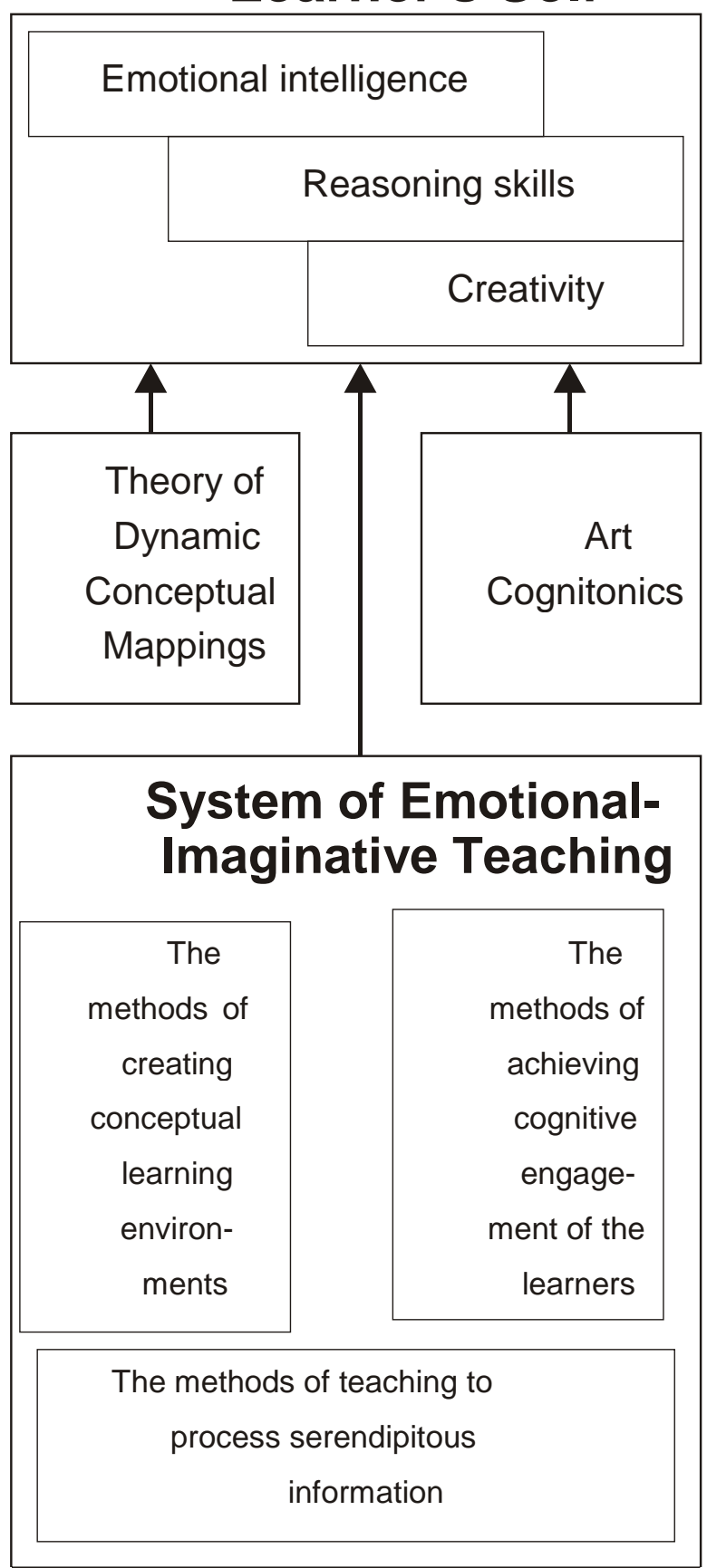

Figure 2: A scheme of a new look at combined development of emotional intelligence, reasoning skills, creativity, and serendipity.

we say that children have reached the level of consciousness development called the level of broad beauty appreciation $[6,15]$. It is important to do before the age of "teen", when children are ready to discuss and follow the social rules. In this case, beauty becomes the core of their system of values $[15,16]$, and it helps a lot at the moment they are twelve and are going on thirteen - the transition age. Figure 2 illustrates a new look at combined development of EI, reasoning skills, and creativity.

The EIT-system includes the original methods of teaching to process serendipitous information. According to Kim [33], a very large scaled study carried out in USA showed that during last decade of the XXth century and first decade of the XXIst century children became less able to connect seemingly irrelevant things. That is why our methods of teaching how to process serendipitous information are very topical.

Well developed feeling of beauty creates for the student the preconditions of being successful at arts lessons. It is broadly accepted to believe that art education supports and develops creativity of young children and teenagers, develops EI, improves emotional well-being, self-confidence, and life skills of the students [42].

The well developed feeling of beauty also creates for the students the preconditions of being successful at art lessons, hence contributes to the success of STEAMed. Hence the broad usage of our approach would contribute to the success of STEAMed.

\section{Art cognitonics and cognitive engagement at art lessons}

Art cognitonics (AC) [16-18] is one of the principal branches of cognitonics, or the science about the human being in the digital world [13 - 15]. The first objective of cognitonics is to explicate the distortions in the perception of the world caused by the information society and globalization. The second, principal objective of cognitonics is to cope with these distortions in different fields by means of elaborating systemic solutions for compensating the negative implications of the kind for the personality and society, in particular, for creating cognitive-cultural preconditions of the harmonic development of the personality in the information society and smart society and for ensuring the successful development of national cultures and national languages.

From the standpoint of educational practice, cognitonics proposes an answer to the following question: what precious ideas and images accumulated by the mankind, at what age, and in what a way are to be inscribed into the world's conceptual picture of a person in order to harmonize his/her intellectual and spirituallycoloured emotional development and to contribute to the successful development of national cultures and national economics?

Cognitonics formulates a new, large-scale goal for the software industry and Web science: to develop a new generation of culture-oriented computer programs and online courses (in the collaboration with educators, linguists, art historians, psychologists) - the computer programs and online courses intended for supporting and developing positively-oriented creativity, emotional intelligence, the appreciation of the roots of the national cultures, the awareness of the integrity of the cultural space in the information and smart society, and for supporting and developing symbolic information processing and linguistic skills, associative and reasoning abilities of children and university students. 
The objectives, ideas, and methods of Cognitonics have been broadly supported by the international scientific community. We successfully organized (as the CoChairs) five international scientific conferences on Cognitonics (Cognit-2009 - Cognit-2017) under the framework of the international scientific multiconferences "Information Society" (IS-2009, IS-2011, IS2013, IS-2015, IS-2017, Slovenia, Ljubljana, Jozef Stefan Institute, October 2009, 2011, 2013, 2015, 2017). The access to the Proceedings of the conferences Cognit-2009 - Cognit-2017 is open, see https://is.ijs.si. A part of cognitonics-based scientific and practical results is presented in the Second Edition of the International Encyclopedia of Social and Behavioral Studies [6].

The DCM-theory and the EIT-system belong to the constructive core of cognitonics. AC aims at tuning the EI of the young children and adolescents with the help of well-known works of art. The goal is to create a bright semantic trace in the world's conceptual picture of the learner corresponding to an idea explaining or illustrating a moral value, communicative situation, a situation of making a decision, cognitive process itself, the process of self-cognition and consideration, the seething cocktail of emotions, a way of viewing the world around, etc.

$\mathrm{AC}$ establishes the links between the objects, situation, processes, views of a person (a beholder) and the work of art that becomes a metaphor or a vivid illustration (vivid mental representation) of something the beholder is considering about. That is why the consciousness of the beholder receives a considerable impulse to developing the ability of establishing diverse analogies and consequently to finding a new look at a situation [16-18].

Example. For enriching the colour of their canvases, the impressionists made use of what is known as division of colour and optical blending. E.g., to represent a green meadow, they put little tabs of blue and yellow on the canvas which are supposed to be combined to form green in the eye of the beholder - a far more intense green than one taken straight from the artist's palette. That is why it is impossible to understand the idea of a picture standing close to the canvas. We have to step aside and look at it from a certain distance to enjoy it and to have the desired effect.

The same situation we have in every-day life. "Multiple debs, reflections" prevent us from grasping the sense of what is happening. As in case with impressionists' canvases, we have to have a look at the situation from a distance, and distance in this case is equal to time distance. We need some time to better understand what has happened, and this will help us to cope with the situation (see another examples in [14]).

The paper [14] contains an algorithm of resisting emotional attacks from social networks by means of transforming the negative emotions into the positive ones. This algorithm is based on the idea described immediately above.

Cognitive engagement $(C E)$ is defined in [15-18] as the process of highly motivated intellectual activity when the interest towards the subject under discussion is so strong that the students loose the track of time and, as a result, they are not tired. The students' interest determines the level of involvement. The emotional response is very close to inspiration, because they are making their own discoveries, and their mental efforts are appreciated. It helps to provide a conceptual learning environment instead of a memorization based one and enhances the motivation. CE is created mainly by the components called in $[15,18]$ focused attention, positive effect, aesthetics, endurance, novelty, motivation.

AC may be interpreted as second successful implementation of the SSOL-model.

\section{A script of an intelligent tutoring system contributing to early socialization of the learners}

During last twenty years, the intelligent tutoring systems (ITSs) have been broadly used throughout the world for helping children and adolescents to grasp theoretical materials. The big subclasses of ITSs help to study (a) second language (SL), (b) mathematics. However, one has been able to find in the literature only separate examples of the systems oriented at developing the personality of the learners. In particular, the interactive multimedia courseware package CITRA is a tool for moral values education using traditional Malay oral narratives [36]. Two collaborative videogames described in $[4,5]$ not only develop mathematical and language skills of the eight ten year old children in Mexico but also support and develop in Mexican children the skill of effective collaboration in a team, hence develop social competence.

The analysis shows that the methods of cognitonics open broad prospects for the development of a new generation of ITSs. Their principal distinguished features should be orientation at culture, at developing EI of the learners. New, culture-oriented scripts under the framework of cognitonics may be divided into three main groups.

Group 1: Socialization-oriented scripts.

The scripts of the kind help to improve the process of better understanding of the goal and the nature of a communicative act. As a result, the acquired communication skills diminish the number of conflicts caused by the misunderstandings and the level of aggression caused by these conflicts.

Group 2. Improvement of the language (mother tongue and SL) as a tool of thinking in order to oppose the phenomenon of poor language and, as a consequence, poor cognitive process, that is, an underdeveloped tool of constructing social reality.

Group 3. The scripts aimed at demonstrating the possibilities of expressing the same idea by means of different languages, e.g., by means of natural language and the language of painting. The goal is the development of the ability to see something extraordinary in an ordinary thing or situation, to find a new look at an object of interest and to make a discovery, to develop the ability of processing serendipitous information. 
Let's consider a script of a culture-oriented ITS based on the idea of social conventions and belonging to the Group 1. The literary source of this script is the fairy-tale "Sleeping Beauty". The script is associated with two aims. The first aim is to explain how it is possible for the student to escape in the life the meeting with the $13^{\text {th }}$ fairy. It means not to make a person act in a provocative way. The reason is that such kind of behaviour would make harm both to an initiator and to a person. In case of the considered fairy-tale, a fairy turned into a witch, because she could not cope with emotions and gave way to hatred. The second aim is to develop the Ecological Self of the student.

\section{Instruction 1 for the designers.}

Construct a dwelling (a hut, a castle, a palace, a cottage, etc.) being appropriate for a King and a Queen and for the $13^{\text {th }}$ fairy. Put the dwelling into appropriate surrounding (garden, park, edge of the forest, etc.).

Choose the interior revealing the characters of the story. Choose the time of the day, the season. Dress the characters up and choose some occupations for them.

\section{Instruction 2.}

According to the logic of Instruction 1, create a big album containing the photos of the characters in different situations. One part of the photos adequately illustrates the life of the personages. Another part falsely illustrates the actions of the personages (in such cases an action or situation contradicts the properties of the character).

Motivate the students to select the photos for the album of each character. The aim of this subsystem of the ITS is to develop the ability of the student to correctly associate the actions of a character with the essence of this character.

\section{Instruction 3.}

Create a subsystem motivating students to construct a dynamic picture showing the extensive preparations in the Kingdom for the Christening Party.

Step 1: The construction of a picture showing all kinds of the living beings (in particular, the carpenter, the animals, and the birds) in the Royal Park.

Step 2: Ask the student to select the living beings for active preparation for the Christening Party.

Step 3: For each considered living being, select one of four - five actions.

Example. It is possible that for the birds a student will select the action "sing the songs".

\section{Instruction 4.}

In general terms, the task is to realize the step explicating the essence of social responsibility. The details of this step are as follows.

The King should be sure that every guest has received the invitation and has accepted the invitation. In order to be sure, the King is to receive a confirmation from every guest that the guest has received and has accepted the invitation. The violation of the rule leads to misunderstanding. In our case, the $13^{\text {th }}$ fairy didn't receive the invitation, though the King had sent an invitation, and regarded the lack of invitation as a mark of disrespect on his part.

Instruction 5. Explain to children how the violation of etiquette will mislead them. Preventing a violation of etiquette means not to make a person act in a provocative way. The reason is that such kind of behaviour would make harm both to an initiator and to a person. In case of the considered fairy-tale, the fairy turned into a witch, because she could not cope with emotions and gave way to hatred. Consider possible examples.

Example 1. One meets a classmate but doesn't greet him/her. It may lead to offense.

Example 2. One may take a pencil of a classmate without the permission. The classmate may become cross with him/her.

Example 3. One may eat a cake without expressing his/her gratitude to a classmate. The classmate may think that he/she is not polite.

Example 4. When he/she does something wrong and doesn't apologize, then the classmate may think that he/she is rude with him/her.

Example 5. When a classmate brings a mouse, though he/she knows that the girl is afraid of mice, it means that he/she is selfish, because he/she doesn't take into account the peculiarities of the girl.

Instruction 6. The essence of this step is to attract the attention to the episodes revealing the behaviour of the character of the book who is thinking and acting in terms of public good.

Example 1. The $12^{\text {th }}$ fairy was attentive and ready to help, she made up the situation and tried to make not only the princess but the whole kingdom fall asleep. The motive of the fairy was not to make the princess lonely when she woke.

Example 2. The people of the kingdom were ready to help, and they brought their spindles to the square to make a fire. They were ready to sacrifice the necessary things and not to have new clothes, because they would not have the spindles to spin.

\section{Instruction 7.}

Preliminary stage. Ask five-six-seven-year-old children being acquainted with the fairy-tale "Sleeping Beauty" to describe the preparations in the Kingdom to the birth of a princess. Construct a collection containing all proposed creatures and their actions of the kind.

Main stage. Ask children to select the creatures and their preparations to the birth of a princess.

\section{Children's speech as a source of vocabulary and images for the designers of tutoring systems}

The inner world's picture of young children is very different from the picture of adults. Young children have 
a vivid imagination, and they easily go from the reality into the world of fantasy. That is why it is very important for the designers of ITSs to use in the computer systems the vocabulary and images extracted from children's examples collected at the preliminary stage of developing a system. We have collected, in particular, the following examples given by children:

\section{Preparation of gifts}

(1) The gardener prepares fountains and flower beds; (2) the carpenter makes the cradle shaped like (a) a swan, (b) dolphin which always rescues, (c) see-shell in which the princess will be like a pearl, (d) a flower which opens its petals at dawn; (3) the beasts prepare (a) milk taken from forest plants, (b) pick up glow-worms; the birds sing songs; the kittens are purring a lullaby; the baby-squirrels have picked up nuts; the mother-dogs are knitting mittens; the mother-squirrels are sewing the dresses for the dolls of the princess.

\section{Preparation in the palace}

(1) The birds are bringing in the beaks the field flowers; (2) the chipmunks are bringing the baskets with drops of dew in order to water field flowers; (3) in the evening the star peeps through the curtain to light the room; (4) the little angel descends in order to fill the nursery with kind dreams and to kiss the princess good night.

\section{Possible directions of future studies}

The considered script allows us to get an initial impression about the possibilities of using the methods of emotionalimaginative teaching as the basis for developing ITSs of a new generation. This script may be compared with a single piece of a big, complicated mosaic picture to be created. The EIT-system provides original effective methods for designing ITSs solving the following tasks:

developing imagination, creativity by means of teaching to decode metaphors and invent metaphors;

contributing to early socialization of the learners on the example of etiquette as a social agreement (etiquette makes the behaviour of the humans predictable, it is very important for understanding each other and in order not to heart the feelings of people);

making thrilling the mastering of SL grammar (on the example of English);

teaching the learners to integrate information dispersed in various sources and to establish timecausal relationships between the extracted facts; revealing cross-culture differences for avoiding misunderstanding during communication.

The EIT-system has been mainly realized at lessons of English as a SL for Russian-speaking children and at the lessons of poetry and literature in English, at lessons devoted to explaining the symbolic language of painting, the culture of communication, and the symbolic language of classical dance. These kinds of lessons are considered in numerous countries as highly appropriate for young children and teenagers. The carefully selected collection of texts used at lessons is provided by a number of classical, world-known fairy-tales and novels, in particular, "Snow White", "Cinderella", "Sleeping Beauty", "Pinocchio", "Pollyanna", "The Life and Adventures of Santa Claus" by L. Frank Baum, "Alice in Wonder Land" by Lewis Carroll, "The Wind in the Willows" by Kenneth Grahame, "The Hundred and One Dalmatians" by Dodie Smith, etc. That is why the EITsystem may be used (after a certain adaptation requiring a small time) in English-speaking countries and in numerous countries where the English language is learned as a SL.

\section{Conclusion}

We believe that the proposed SSOL-model possesses the properties enabling its usage as a paradigm for education in KS. The focus on the student's Self at the lessons means that the lessons are emotionally coloured, and this very much contributes to the success of the learning process.

Now there are at least two successful implementations of the SSOL-model: the EIT-system, tested during 28 years in Russia, and art cognitonics. The principal distinguishing feature of the EIT-system is an effective, many-staged method of sustaining and developing creativity in young children and adolescents, supporting and developing EI, basing on EI for making much easier the grasping of the materials to be studied.

Our numerous publications in English describe many aspects of the EIT-system. The scholars from various countries do have the possibility to develop their original implementations of the SSOL-model with respect to their mother tongue and national culture. The stated ideas and the EIT-system provide a strong support to STEAM education and to anthropocentric approach to education in the digital age as a whole.

\section{Acknowledgement}

We are grateful to the anonymous reviewers of our paper for precious remarks.

\section{References}

[1] Bradberry, T. (2014). Emotional Intelligence - EQ; http://www.forbes.com/sites/travisbradberry/2014/0 1/09/emotional-intelligence/\#216e16f61ac0; retrieved 21.07.17.

[2] Craft, A. (2001). Little c creativity. In A. Craft, B. Jeffrey and M. Leibling (Eds.), Creativity in Education. Continuum, London, 45-61.

[3] Craft, A. (2005). Creativity in Schools: Tensions and Dilemmas. Routledge, Abingdon. https://doi.org/10.4324/9780203357965

[4] Craig, P., Roa-Seïler, N., Martínez Díaz, M., and Lara Rosano, F. (2013). Assessing the Potential of Colaborative Video Games to Improve Education in La Mixteca Region of Mexico. In: Gams, M., Piltaver, R., Mladenic, D. et al., Eds. (2013). Proceedings of the $16^{\text {th }}$ International 
Multiconference Information Society - IS 2013, Slovenia, Ljubljana, 7 - 11 October 2013. The Conference Kognitonika/Cognitonics. Jozef Stefan Institute; pp. 413-417; https://is.ijs.si/archive/proceedings/2013/ .

[5] Craig, P., Roa-Seiler, N., Martínez Díaz, M., and Lara Rosano, F. (2014). A Cognitonics Approach to Computer Supported Learning in the Mexican State of Oaxaca. Informatica. An Intern. Journal of Computing and Informatics, 38, 3, pp. 241-248.

[6] Fomichov, V. A. (2015). Conscious Control during Childhood, Development of. In International Encyclopedia of the Social and Behavioral Sciences, Second Edition .Vol. 4. Elsevier, Oxford, pp. 666672. https://doi.org/10.1016/B978-0-08-0970868.23082-1.

[7] Fomichov, V. A., Fomichova, O. S. (1994). The Theory of Dynamic Conceptual Mappings and its Significance for Education, Cognitive Science, and Artificial Intelligence. Informatica. An International Journal of Computing and Informatics, Vol. 8, No. 2, pp. 31-148.

[8] Fomichov, V. A., Fomichova, O. S. (1995). The artificial intelligence theory and highly effective methods of teaching young children foreign languages. Cybernetica. XXXVIII, pp. 321-344.

[9] Fomichov, V.A., Fomichova, O.S. (1997). An Informational Conception of Developing the Consciousness of the Child. Informatica. An Intern. Journal of Computing and Informatics (Slovenia), Vol. 21, pp. 371-390.

[10] Fomichov, V., Fomichova, O. (1998) A new theoretical and practical approach to early positive developing child's consciousness. In $R$. Trappl (Editor), Cybernetics and Systems'98. Proceedings of the 14th European Meeting on Cybernetics and Systems Research. Vol. 1, Austrian Society for Cybernetic Studies, Vienna, pp. 276-281.

[11] Fomichov, V.A., Fomichova, O.S. (1998). Early development of natural-language-processing abilities as a key to up-bringing of children without conflicts. In: G. Ritschard, A. Berchtold, F. Duc, D.A. Zighed (Eds). Apprentissage: des principes naturels aux methodes artificielles. Editions HERMES, Paris, pp. 67-81.

[12] Fomichov, V. A., Fomichova, O. S. (2000). The social responsibility of computer science specialists for the creative potential of the young generation. Intern. Journal of Artificial Intelligence in Education. Vol. 11, pp. 208-219.

[13] Fomichov, V.A., Fomichova, O. S. (2006). Cognitonics as a New Science and Its Significance for Informatics and Information Society; Informatica. An Intern. Journal of Computing and Informatics (Slovenia), Vol. 30, pp. 387-398.

[14] Fomichov, V. A., Fomichova, O. S. (2012). A Contribution of Cognitonics to Secure Living in Information Society. Informatica. An Intern. Journal of Computing and Informatics, Vol. 36, pp. 121-130.
[15] Fomichov, V.A., Fomichova, O.S. (2014). An Imperative of a Poorly Recognized Existential Risk: Early Socialization of Smart Young Generation in Information Society. Informatica. An International Journal of Computing and Informatics, Vol. 38, No. 1, pp. 59-70.

[16] Fomichov V. A., Fomichova, O. S. (2015). Early Development of the Human Being Ideal Constituent and Art Cognitonics as the Answer to the Challenge of Knowledge Society. In: Informacijska druzba - IS 2015. Proc. of the 18th International Multiconference - IS 2015, Edited by V. A. Fomichov, $O . \quad$ S. Fomichova. Vol. F: Kognitonika/Cognitonics. Oct. 12th-13th, 2015, Ljubljana. Jozef Stefan Institute, pp. 27-32.

[17] Fomichov, V. A., Fomichova, O. S. (2017). The Student-Self Oriented Learning Model as a Paradigm for Supporting and Developing Emotional Intelligence and Creativity.In Informacijska druzba IS 2017. Proceedings of the 20th International Multiconference - IS 2017, Edited by V. A Fomichov, $O$ S. S. Fomichova. Vol. Kognitonika/Cognitonics. October 9th-10th, 2017, Ljubljana, Slovenia. Jozef Stefan Institute, Ljubljana, pp. 11-16.

[18] Fomichov, V. A., Fomichova, O. S. (2018). Cognitonics and Its Significance for Education in the Digital Age. Moscow, Publishing House MAKS Press. 344 p. (in Russian).

[19] Fomichova, O.S., Fomichov, V.A. (1996). Theoretical Foundations of a New Method of Teaching Children Effective Information Processing. Informatica. An Intern. Journal of Computing and Informatics, Vol. 20, pp. 381-399.

[20] Fomichova, O. S., Fomichov, V. A. (2000). Computers and the Thought-Producing Self of the Young Child; The British Journal of Educational Technology, Vol. 31, No. 3, pp. 213-220. https://doi.org/10.1111/1467-8535.00152.

[21] Fomichova, O.S., Fomichov, V.A. (2003). A new paradigm for constructing children-oriented websites of art museums. Intern. Journal of Educational Technology and Society, Vol. 6, No. 3, pp. 24-29.

[22] Fomichova, O. S. and Fomichov, V. A. 2009. Cognitonics as an Answer to the Challenge of Time. In Proceedings of the $12^{\text {th }}$ International Multiconference Information Society - IS 2009, Slovenia, Ljubljana, 12 - 16 October 2009. The Conference Kognitonika/Cognitonics. Jozef Stefan Institute, Ljubljana, 2009, pp. 431-434..

[23] Fomichova,, O. S., Fomichov, V. A. (2017). The Methods of Cognitonics as the Basis for Designing Intelligent Tutoring Systems Developing Emotional Intelligence of the Learners. In Informacijska druzba - IS 2017. Proc. of the 20th Intern. Multiconference - IS 2017, Edited by V. A. Fomichov, O. S. Fomichova. Vol. Kognitonika/Cognitonics. October 9th-10th, 2017, Ljubljana, Slovenia. Jozef Stefan Institute, Ljubljana, pp. 17-21.

[24] Gardner, H. (1993). Creating Minds: an Anatomy of Creativity Seen Through the Lives of Freud, 
Einstein, Picasso, Stravinsky, Eliot, Graham, and Gandhi. Basic Books, New York.

[25] Goleman, D. (1995). Emotional Intelligence. Bantam Books, New York.

[26] Goleman, D. (2016). Emotional Intelligence; http://www.danielgoleman.info/topics/emotionalintelligence; retrieved 12.09.2016.

[27] Goy, P. (2015). Pre-school kids play and learn. The Straits Times, Nov. 23, 2015; http://www.straitstimes.com/singapore/pre-schoolkids-play-and-learn (retrieved 14.12.2017).

[28] Hom, E.J. (2014). What is STEM Education. LiveScience, Feb. 11, 2014; https://www.livescience.com/43296-what-is-stemeducation.html (retrieved 10.12.2017).

[29] Hornby, A. S. (1995). Oxford Advanced Learner's Dictionary of Current English. Fifth edition. Oxford University Press.

[30] Kane, T. B. (2014) Using Cognitive Tunnels in a New Approach to Building Social Elevators in the Information Society. Informatica. An International Journal of Computing and Informatics (Slovenia), Vol. 38, pp. 263-271.

[31] Kim, B.-H., Lim, Y.-D., Jung, M.-Y. et al. (2017). The effects of STEAM class using science-art-IT convergence art work for middle school education under a free semester system in Korea. International Workshop on Intelligent Information Technology (2WINTECH), Cheonan, South Korea, Oct. 20-22, 2016. Advanced science letters, Vol. 23, No. 3, pp. 1700-1704. https://doi.org/10.1166/asl.2017.8634.

[32] Kim, D., Bolger, M. (2017). Analysis of Korean elementary pre-service teachers' changing attitudes about integrated STEAM pedagogy through developing lesson plans. Intern. journal of science and mathematics education. Vol. 15, No, 4, pp. 587605. https://doi.org/10.1007/s10763-015-9709-3.

[33] Kim, K. H. (2011). The creativity crisis: the decrease in creative thinking scores on the Torrance Tests of Creative Thinking. Creativity Research Journal. Vol. 23, No. 4, pp. 285-295. https://doi.org/10.1080/10400419.2011.627805

[34] Kudryavtsev, V. T. (2011). The phenomenon of child creativity. International Journal of Early Years Education. Vol. 19, No. 1, pp. 45-53. https://doi.org/10.1080/09669760.2011.570999.

[35] Maeda, J. (2012). STEM to STEAM; Art in K-12 is key to building a strong economy. EDUTOPIA. George Lucas Educational Foundation, Oct. 2, 2012; https://www.edutopia.org/blog/stem-to-steamstrengthens-economy-john-maeda (retrieved 14.02.2018).

[36] Mukti, N.A., Hwa, S.P. (2004). Malaysian perspective: designing interactive multimedia learning environment for moral values education. Educational Technology and Society. Vol. 7, No. 4, pp. 143-152.

[37] Neisser, U. (1997). The roots of self-knowledge: perceiving Self, It, and Thou. In: Snodgrass, J.G. and Tompson, R.L. (eds.). The Self Across Psychology. Self-Recognition, Self-Awareness, and the Self
Concept. Annals, Vol. 818. The New York Academy of Sciences, pp.19-33. https://doi.org/10.1111/ j.1749-6632.1997.tb48243.x.

[38] OECD (2010). A Family Affair: Intergenerational Social Mobility across OECD Countries, in OECD, Economic Policy Reforms 2010: Going for Growth, OECD Publishing. Doi: 10.1787/growth-2010-38en. https://doi.org/10.1787/growth-2010-38-en.

[39] Padovan, C., Versace, R. (1998). The represen-tation of emotion in long term memory. Apprentissage: des principes naturels aux methodes artificielles, sous la direction de G. Ritschard, A. Berchtold, F. Duc, and D.A. Zighed. Editions HERMES, Paris, pp. 111-123.

[40] Piaget, J. (1981). Creativity. In J. M. Gallagher and D. K. Reid (Eds.), The Learning Theory of Piaget and Inhelder. Brooks-Cole, Monterey, CA, pp. 221229.

[41] Pomeroy, R.S. (2012). From STEM to STEAM: Science and Art Go Hand-in-Hand. Scientific American, Aug. 22, 2012;

https://blogs.scientificamerican.com/guestblog/from-stem-to-steam-science-and-the-arts-gohand-in-hand/ (retrieved 14.02.2018).

[42] Roege, G. B., Kim, K. H. (2013). Why we need arts education. Empirical Studies of the Arts. Vol. 31, No. 2, pp. 121-130. https://doi.org/10.2190/EM.31.2.EOV.1

[43] Sawaizumi, S., Katai, O., Kawakami, H., Shiose, T. (2007). Using the concept of serendipity in education. Proc. of the KICSS 2007: The Second International Conference on Knowledge, Information and Creativity Support Systems, Nomi, Ishikawa, Japan. JAIST Press; https://dspace.jaist.ac.jp/dspace/handle/10119/4087

[44] Searle, J. R. (1995). The Construction of Social Reality. The Penguine Press.

[45] The Sutton Trust, Educational Backrounds Reports, http://www.suttontrust.com/ourwork/research/professions/

[46] US Public Health Service. Report on the Surgeon's General's Conference on Children's Mental Health: a national action agenda (2000). Washington, DC., Department of Health and Human Services. 
